Part of Journal of Research of the National Bureau of Standards, Volume 15, December 1935

\title{
STABILITY OF AQUEOUS SOLUTIONS OF ACID POTASSIUM PHTHALATE
}

\author{
By James I. Hoffman
}

ABSTRACT

The tests described show that aqueous solutions of acid potassium phthalate stored in tightly stoppered flasks do not decompose under the conditions existing in the average chemical laboratory.

Occasional inquiries at this Bureau indicate that some chemists prefer to take aliquot portions of a master solution of acid potassium phthalate for the standardization of alkaline solutions rather than to weigh separate portions of the reagent for each titration. There has been considerable doubt concerning the "keeping" qualities of a solution of acid potassium phthalate. The following tests were therefore made.

A solution was prepared by dissolving $10.0000 \mathrm{~g}$ of acid potassium phthalate (National Bureau of Standards Standard Sample 84) in distilled water and diluting to 1 liter in a volumetric flask made of soft glass. After thorough mixing, about one-half of this solution was transferred to a dry Pyrex flask. Both flasks were closed with tightly fitting glass stoppers which were sealed with Cementyte. The regular supply of distilled water was used, and no attempt was made to sterilize it. After allowing the solutions to stand for 1 year in a cupboard in a north laboratory, $100.00-\mathrm{ml}$ portions (equivalent to $1.0000 \mathrm{~g}$ of phthalate) were withdrawn and titrated with an approximately $0.15 \mathrm{~N}$ solution of sodium hydroxide. At the same time $1.0000-\mathrm{g}$ portions of acid potassium phthalate from the same lot were dissolved in $100 \mathrm{ml}$ of distilled water and immediately titrated with the $0.15 \mathrm{~N}$ sodium hydroxide solution. All the results agreed within 1 part in 3,000 .

The flasks were again tightly sealed, and the solutions remaining in the flasks were then exposed outdoors to direct sunlight, 2 to 5 hours at a time, during June, July, and August. The total time of exposure to direct sunlight was 75 hours, but the elapsed time was 3 months. Comparative titrations again showed an agreement within 1 part in 3,000 between $100.00-\mathrm{ml}$ portions of these solutions and solutions freshly prepared by dissolving $1.0000 \mathrm{~g}$ of phthalate in $100 \mathrm{ml}$ of distilled water.

Volumetric glassware was specially calibrated for this work, and the temperature of the solutions at the time of preparation and withdrawal of the aliquot portions was the same $\left(27^{\circ} \mathrm{C}\right)$. Weight burettes were used in all titrations. The solutions remained clear, and there was no evidence of fungous growth. 
The tests show that, under the conditions existing in the average laboratory, standard aqueous solutions of acid potassium phthalate do not change in strength and can be used in acidimetry if desired. However, the use of such solutions has not been adopted at this Bureau because the present procedure of weighing the phthalate, dissolving it in water, and immediately titrating the solution with alkali is so extremely simple.

Washington, October 2, 1935. 